\title{
Process of Measuring in Clinical Medicine - Implications of Different Definitions in Clinical Therapeutic Studies
}

\author{
Andree Beckerling Waldemar Braun Michael Sommer \\ IFE Institute for Research and Development at the University Witten/Herdecke, Witten, Germany
}

\section{Key Words}

Symptomatic healing $\cdot$ Measurement error .

Gastroesophageal reflux disease

\begin{abstract}
Often, the decision whether a patient can be considered as healthy or ill is very difficult and depends on measurements and the interpretation of the results. Therefore, it is necessary to build and establish devices that base on certain pre-considerations (who should assess the data, when and how should be measured). Additionally, these devices have to be valid, reliable and responsive. According to the literature we came to the conclusion that no uniform definition of what is 'healthy' exists. Referring to mathematical considerations we show an approach to solve this problem especially when the device is a scale. Based on the quality of the scale and of certain pre-considerations normal ranges can be established that will help to distinguish whether patients are 'healthy' or 'ill'. In this short review we discuss the problem of the establishment of a cut-off level on the basis of devices and we try to point out a solution to solve the arising problems.
\end{abstract}

Copyright $\odot 2004$ S. Karger AG, Basel

\section{Background}

What do we know about measuring, the process of measuring, and the corresponding implications for daily clinical practice? What is measuring? What is normal? What is abnormal?

Measurement is a generally simple but complex activity in daily practice in a broad spectrum of medical indications. Normally, measuring laboratory values results in normal reference ranges with a lower and upper normal limit. Using these normal reference ranges and deviations thereof, different clinical parameters for patients can be assessed. Regarding certain laboratory parameters, a patient can be considered as 'healthy' or 'ill', or 'intermediate', which makes the clinical use of these parameters difficult. These indifferent assessments of parameters do not only apply for laboratory values but also for a huge variety of measurement methods in different indications. For all indications, the same questions apply: What is the definition of 'normal'? What is the medical meaning of 'not normal'? What is 'intermediate'? What are the implications of these definitions for the use of parameters as a diagnostic tool? What does it mean for the follow-up assessment? From a methodological point, it is clear that parameters used as a diagnostic tool need a high specificity for the disease to be diagnosed, whereas the same parameters used as a tool for the follow-up assessment need

\section{KARGER}

Fax +4161306 1234 E-Mailkarger@karger.ch www.karger.com www.karger.com/dig
Andree Beckerling

IFE Institute for Research and Development

University Witten/Herdecke GmbH, Alfred-Herrhausen-Strasse 44

DE-58455 Witten (Germany)

Tel. +49 2302921 5, Fax +492302921 600, E-Mail office@ife-europe.com 
a high sensitivity. Can a tool, designed for diagnosis, even be used for follow-up assessment? To come back to the laboratory parameters, the use of, e.g., the creatinkinase (CK) and its isoenzyme CK-MB were used as one out of four criteria in the diagnosis of patients with acute cardial ischemia for a long time, and it is an accepted tool for the follow-up assessment [1].

The medical need as well as the methodological requirements can be elucidated by means of a clinical example. During the last years, numerous clinical studies aiming to show the therapeutic benefit of proton pump inhibitors (PPI) in the treatment of gastroesophageal reflux disease (GERD) have been published. The control of gastric acid secretion is the key factor in healing of the disease. Numerous studies demonstrated the close correlation between the extent of inhibition of acid secretion and the therapeutic success $[2,3]$. In most cases, PPIs achieve the desired acid suppression when given once daily and are accepted to be the best treatment option. Often, these trials are designed to demonstrate the clinical benefit of these PPIs or to show differences between these drugs. Obviously, the outcome criteria in these trials focus on either symptomatic relief or endoscopically proven mucosal healing. By means of the different classifications used for GERD, the definition of endoscopically proven healing is precisely defined.

However, a unique and generally accepted definition of symptomatic relief is missing. Most often, trying for clearness and precision, the presence or absence of socalled typical GERD symptoms is used for diagnosis and definition of symptomatic relief of GERD. The symptoms heartburn and acid eructation are generally accepted to be of relevance for the diagnosis of GERD, although it is known that up to $40 \%$ of patients with erosive GERD do not suffer from heartburn [4]. Otherwise it is not clear whether the pure absence of these symptoms is sufficient for the definition of symptomatic relief. In daily clinical practice, patients are declared to be symptomatically healed after a standard treatment course when they are free of heartburn and/or acid eructation, or generally, free of symptoms they initially suffered from. But what does 'free of symptoms' exactly mean? It is clear that this very puristic approach does not reflect clinical reality as even healthy individuals suffer from the symptoms from time to time [unpublished data].

It becomes more and more accepted that other upper and lower abdominal symptoms and symptom patterns as for example epigastric pain, upper abdominal pressure, flatulence, or diarrhea are often observable in patients with proven erosive GERD. How do these symptoms de- scribed as dyspepsia and/or irritable bowel syndrome (IBS) symptoms have to be regarded? More generally spoken, which symptoms have to be considered for and how do the dimensions intensity, time, and frequency affect the definition of symptomatic healing? Obviously, the definition of being symptomatically relieved cannot be limited to the absence of symptoms considered to be typical of GERD. Consequently, a wide range of definitions for symptomatic relief is used in the current literature. Referring to these definitions, it becomes clear that this is not basically a question of definition but mainly a question of the process of measuring symptoms.

The process of measuring with medical devices involves certain errors and a certain variability. They are caused by the device itself but also by physicians or patients using the device. Great efforts are made to control this uncertainty by calibration and adjustments. Usually, we expect to have normal ranges and measurement errors. For simple measurements like weight, height, etc., we know about possible measurement errors, and we have a normal range table for these parameters depending on age and sex.

For measuring complicated symptoms, self-created diaries are often used. Astonishingly, we do not examine the error of these measurements which is even more surprising because the measurement is done by the patients themselves. As patients are far from being experts in the field of measuring, it has to be taken into account that mistakes are made and the measurement may be biased.

Referring to examples from the literature we will deduce the typical problems of symptom measurement and the variability of symptom measurement in GERD patients. The inconsistencies, tat will be illustrated, can be found in other medical areas as well. With respect to the specific GERD questions raised above, we propose to define the terms 'symptom free' and especially 'heartburn free' in a more scientific way.

\section{Examples}

Damiano et al. [5] recorded the severity of GERD-associated symptoms in a diary daily. Severity was rated on a five-point scale from 'no' (0) to 'very severe' (4). The symptoms assessed were daytime heartburn, night-time heartburn, belching, regurgitation, early satiety, bloating, nausea, and vomiting. Complete heartburn relief was defined as no heartburn symptoms during seven days prior to follow-up assessment and satisfactory heartburn relief 
as no more than one episode of moderate heartburn during seven days prior to follow-up assessment.

In a meta-analytical study, Chiba et al. [6] identified 16 studies in which the responsible authors presented both the number of patients who started out with grade II to IV (according to Savary/Miller modified by Sievert) esophagitis and reported heartburn and the proportion of patients who reported complete symptom relief. Although these studies were analyzed well, a specific definition of complete symptom relief is missing in this paper.

A typical trial to overcome the problems of measurement, i.e. the different points of view of investigators and patients lead to different results concerning symptom relief, can be found in a manuscript by Lind et al. [7]. They compared omeprazole $20 \mathrm{mg}$ vs. omeprazole $10 \mathrm{mg}$ vs. placebo. The patients recorded frequency and severity of heartburn in a diary during 4 weeks of treatment and at the visits after 2 and 4 weeks of treatment. In relation to 'symptomatically healed', they established the following definitions: (1) complete absence of heartburn: no episodes of heartburn during the 7 days before clinical visit (investigator); (2) resolution of heartburn: no more than one day with mild episodes of heartburn during the past 7 days (investigator); (3) free of heartburn (patient), and (4) sufficient control of heartburn (patient). The results obtained after four weeks are summarized in table 1 . Table 1 shows both a systematic underestimation of heartburn by the investigator and the broad range of rates depending on the measurement and the definition.

Johnson et al. [8] compared the efficacy of esomeprazole $40 \mathrm{mg}$ vs. esomeprazole $20 \mathrm{mg}$ vs. placebo. Patients had to record the severity of heartburn during the preceding 24-hour period in a diary card. In this study, the primary criterion was the complete resolution of heartburn (severity was defined as 'none') during a time interval of $24 \mathrm{~h}$. The secondary criterion was the investigators' assessment of heartburn. For this, only the last three days prior to the visit were assessed. They received the results demonstrated in table 2. Besides the fact that investigators' and patients' assessment cannot be compared due to the different time intervals chosen, it seems that the longer interval of three days compensates the usual underestimation of the investigator.

Richter et al. [9] compared the efficacy of omeprazole $20 \mathrm{mg}$ vs. omeprazole $10 \mathrm{mg}$ vs. placebo. All efficacy data regarding heartburn were recorded in a patient diary. The investigator recorded other symptoms like acid regurgitation, dysphagia, epigastric pain, and nausea. The primary efficacy criterion was the proportion of patients with no
Table 1. Systematic underestimation of heartburn by the investigator and the broad range of rates depending on kind of measurement and definition

\begin{tabular}{llll}
\hline & $\begin{array}{l}\text { Omeprazole } \\
20 \mathrm{mg}, \%\end{array}$ & $\begin{array}{l}\text { Omeprazole } \\
10 \mathrm{mg}, \%\end{array}$ & $\begin{array}{l}\text { Placebo } \\
\%\end{array}$ \\
\hline Complete absence, investigator & 46.3 & 31.1 & 13.3 \\
Resolution, investigator & 61.0 & 49.3 & 23.8 \\
$\begin{array}{l}\text { Free of heartburn, patient } \\
\text { Sufficient control, patient after }\end{array}$ & 65.0 & 64.0 & 38.0 \\
$\quad$ 2 weeks & 64.0 & 59.0 & 32.0 \\
\hline
\end{tabular}

Table 2. Different assessments of absence of symptoms separated by investigators or by patients

\begin{tabular}{llll}
\hline & $\begin{array}{l}\text { Esomeprazole } \\
40 \mathrm{mg}, \%\end{array}$ & $\begin{array}{l}\text { Esomeprazole } \\
20 \mathrm{mg}, \%\end{array}$ & $\begin{array}{l}\text { Placebo } \\
\%\end{array}$ \\
\hline $\begin{array}{c}\text { Complete absence, } \\
\text { patient after 24 h }\end{array}$ & 67 & 62 & 21 \\
$\begin{array}{c}\text { Complete absence, } \\
\text { investigator after 3 days }\end{array}$ & 71 & 65 & 16 \\
\hline
\end{tabular}

Table 3. Comparison of the efficacy of omeprazole $20 \mathrm{mg}$ vs. omeprazole $10 \mathrm{mg}$ vs. placebo with regard to complete absence of heartburn as the leading symptom (assessed by the patients)

\begin{tabular}{lllr}
\hline & $\begin{array}{l}\text { Omeprazole } \\
20 \mathrm{mg}, \%\end{array}$ & $\begin{array}{l}\text { Omeprazole } \\
10 \mathrm{mg}, \%\end{array}$ & $\begin{array}{l}\text { Placebo } \\
\%\end{array}$ \\
\hline Complete absence, day 27 & 74 & 49 & 23 \\
Complete absence, days 21-27 & 48 & 27 & 5 \\
\hline
\end{tabular}

heartburn each day and the complete resolution of heartburn, i.e. no heartburn at all during the last seven days prior to the corresponding symptom assessment. The results after 4 weeks are illustrated in table 3 . This example underlines that the period of assessment of symptoms plays an important role and therefore has to be considered.

Hatlebakk et al. [10] compared the efficacy of omeprazole $20 \mathrm{mg}$ vs. cisapride $20 \mathrm{mg}$ vs. placebo. The primary criterion was adequate control of heartburn defined as less than or equal to 1 day with at most mild heartburn during 7 days prior to the follow-up visit after 4 weeks of treatment. Heartburn was defined as burning substernal discomfort with no radiating component and was described in common words. As a result, $71 \%$ of the patients 
(omeprazole) reported an adequate control of heartburn, in contrast to 22\% (cisapride) and 18\% (placebo).

In the trial of Richter et al. [11], lansoprazole $30 \mathrm{mg}$ and omeprazole $20 \mathrm{mg}$ were compared. The primary criterion was frequency and severity of heartburn experienced on the first day of treatment and during the last 3 days prior to the beginning of treatment. Episodes of heartburn were recorded in diaries. Additionally, phone calls were conducted to ensure diary entries by the patients. They achieved healing rates of 56\% (lansoprazole) and $49 \%$ (omeprazole).

Further definitions of symptom relief used in other clinical trials are [12-14]: (1) median time to achieve the first 24-hour interval without heartburn; (2) satisfactory heartburn relief: no ore than one episode of moderate severity during a preceding interval of seven days; (3) time to first and sustained resolution of heartburn; (4) total relief of symptoms on the fourth day of treatment defined as no or only mild heartburn, and (5) no more than one episode of moderate heartburn during 7 days.

\section{Conclusions from the Examples}

There is a wide variety and in some sense arbitrariness in the definition of symptom relief. The researchers have the opinion that total relief of symptoms is a completely artificial construct and does not reflect total relief of symptoms from a medical point of view. Thus, they try to establish reasonable definitions, which seem to reflect medical knowledge.

The analysis of the examples leads to the following conclusion: Severity is often defined as 'none', 'mild', 'moderate', or 'severe'. Does this rating emphasize enough differences? Can patients classify their symptoms in these categories? It is an essential question how frequency and severity of symptoms are combined to draw conclusions about the whole impact of a disease. The global term 'distress' gives more information about a disease in addition to symptoms. Several time intervals were chosen in the examples in which symptom relief should have taken place such as ' 7 days', ' 1 day', 'the last 24 h', or 'the last 3 days'. The reason for these different time intervals is the uncertainty about the frequency of episodes in GERD patients. Although it is known that GERD symptoms occur episodically, nearly nothing is known about the frequency and duration of episodes. To choose an appropriate time interval, the probability of an episode in a certain time interval should be reflected on.

To be able to judge what is thought to be 'mild' or 'moderate' regarding the severity of symptoms, it is es- sential to know what can be defined as 'normal'. It is well known that healthy individuals sometimes suffer from heartburn, but it is important to know the frequency of these episodes in healthy individuals. On that basis, it is difficult to define what is commonly regarded as 'normal'. Which symptoms should be considered? Heartburn is known as a predominant symptom. A great proportion of patients are free of heartburn after a short time treatment with a PPI. However, it is generally accepted [15] that these patients with heartburn suffer from other associated symptoms during and after treatment with PPIs, too. These symptoms have great influence on the patients' well-being and quality of life. The question is whether these symptoms can be included in a concept describing symptomatic healing.

\section{Measurement of Symptoms}

Measurement of symptoms is comparable to the measurement of blood pressure or the measurement of peak flow, for instance, with the exception that measurement of symptoms turns out to be very complicated. This is due to the fact that several factors have to be considered like the choice of words or who is the rater, investigator or patient. Independent from the person applying the diary the tool has to be constructed like a peak flowmeter or a lab analyzer. After construction, the psychometric properties of the tool must be examined. Usually, this process is done using the classical test theory (CTT) on the basis of psychometrical analyses. For description of the application in medical areas please refer to De Coster [16] and Atkinson et al. [17]. A scale should have at least the following properties.

\section{Validity}

Validity is the degree to which a scale measures what it is purported to measure. With reference to the purpose, the scale is developed for several calculable validities, e.g. content validity, construct validity, or criterion validity.

\section{Reliability}

Reliability describes the steadiness of a scientific experiment. It determines the degree of accuracy of a scientific scale and depends directly on the measurement error. In this context, it is imperative that the lower the measurement error the greater the reliability. One alternative to determine reliability of a scale is to calculate the internal consistency by means of Cronbach's alpha [18]. 


\section{Responsiveness}

This psychometric property describes the power of a scale to detect relevant changes in the target population. The higher the value, the greater the responsiveness [19].

\section{General Observations}

On the basis of the CTT, the model dealing with the measurement error is exactly the same as a model based on medical devices. The idea is to claim the existence of a 'true' underlying value, such as peak flow, weight, etc., and that the observed value obeys the following demand:

Observed value $=$ True value + measurement error .

Assuming that the true value and the error term are independent, the standard deviation is the square root of the sum from the variance of the true value and the variance of the error:

$$
\sqrt{\sigma_{\text {true }}^{2}+\sigma_{\text {error }}^{2}}
$$

This standard error is obviously greater than the standard error of the true value. By simple operations, it can be concluded for the measurement error:

$$
\mathrm{m}=\sigma_{\text {error }}=\sigma_{\text {observed }} \sqrt{1-\frac{\sigma_{\text {true }}^{2}}{\sigma_{\text {observed }}^{2}}}
$$

As we know $\frac{\sigma_{\text {true }}^{2}}{\sigma_{\text {observed }}^{2}}$ is nothing else than the reliability $r$ of a scale. Therefore, we end up with the very essential practical formula for the measurement error:

$$
\mathrm{m}=\sigma_{\text {error }}=\sigma_{\text {observed }} \sqrt{1-\mathrm{r}}
$$

Thus, the error can be easily estimated if the reliability is known. If the reliability of the measurement of the blood pressure is 0.84 , the square root with reference to equation (2) is 0.4. Thus, assuming a blood pressure of $80 \mathrm{~mm} \mathrm{Hg}$ is measured with a standard deviation of $15 \mathrm{~mm} \mathrm{Hg}$, the measurement error is $6 \mathrm{~mm} \mathrm{Hg}$. In clinical trials, a clinically relevant difference of $5 \mathrm{~mm} \mathrm{Hg}$ is stated. Against the background of this example, the measurement error is greater than the clinically relevant difference. Thus, it is senseless to insist on this clinical relevance, because relevant differences cannot be estimated in a correct way. From these considerations, a very essential requirement results: i.e. clinically relevant difference measurement error.

If nothing is known about what is clinically relevant, it is reasonable to use the measurement error.

\section{Norm and Normal}

The normal status and the pathological status of a patient are two pillars of medicine. The normal status is without any symptoms and not perceived [20].

The pathological status is defined as deviation from the normal status [20]. From this and from the above derived calculations concerning the measurement error, it can be concluded that all measurements which fall within the range of the measurement error must be seen as a normal status, because deviations from the normal status cannot be detected in that case. Thus, for symptom scores below the measurement error, there are no alternatives as to define them as normal. If done so, it is essential to have a method to detect when the normal status is reached. Insofar as the measurement error restricts our definition of a normal status whatever is done to find other definitions.

Another concept to define the normal status is to define 'normal' as what is observed in the majority of healthy individuals. For that epidemiological surveys have to be conducted in healthy people to provide an overview about deviations from known symptomatology and distresses. On the basis of this, comparative conclusions can be drawn of what should be called 'normal' and what 'pathological'.

\section{Discussion}

When measuring symptoms, values, laboratory parameters, etc., certain criteria have to be fulfilled. With respect to the classical test theoretical approach, reliability, responsiveness, and different validities have to be demonstrated or at least considered. Additionally, the measurement error is a helpful instrument to demonstrate or decide what is normal and what is a clinically relevant difference between two groups.

When reviewing papers describing clinical trials, as we have shown for GERD, we should always ask for these criteria, especially when strict conclusions are drawn from direct comparisons.

With reference to the examples outlined above, most clinical trials using symptom assessment as primary outcome criterion lack of fulfilling these criteria. A definition for 'normal' based on the test theoretical approach is usually missing. However, conclusions of differences between two treatment groups are often below the measurement error. As deduced in this review, if differences between measurements are within the range of the measurement error, these differences cannot be stated as clinically relevant. 
To show these implications, we take the data from Richter et al. [11]. The severity of symptoms in their study was recorded by the patients in a daily diary as 'none', 'mild', 'moderate', 'severe', or 'very severe'. The average heartburn severity in the lansoprazole group was 0.62 with a standard deviation of 0.69 and in the omeprazole group 0.74 with a standard deviation of 0.72 . The authors stated that heartburn severity was significantly $(p<0.0001)$ lower in the lansoprazole group. The authors as well as the readers do not know how precisely the diary measures heartburn, because it was not estimated. For our purpose we assume a high reliability, e.g. $r=0.8$ or even 0.9 demonstrating a best case scenario. For a standard deviation of 0.7 , we get a measurement error using the above-mentioned equation (2) of 0.31 in case of $r=$ 0.8 and 0.22 in case of $r=0.9$. Thus, the measurement error is nearly twice the difference between the values of the treatment group.

Therefore, any conclusion about the relevance of the significant difference is very doubtful. As a result, we clearly state, based on the examples, that clinical trials in GERD often lack the requirements described in ICH E9 [CPMP/ICH/363/96 2.2.3] saying that only validated tools are allowed to be used as primary outcome parameters.

These considerations show that there is an outstanding need for improving symptom measurements and for bringing symptom measurement to a quality standard well known and required in other medical areas.

The remarks above show clearly the problems and difficulties in judging the patients' health status and the problems to decide whether a patient is treated effectively. The examples show that there are several approaches in medicine to define symptomatic relief in patients suf- fering from GERD, but this paper demonstrates that all these approaches lack of adequate pre-considerations or psychometric analyses. How a scale should be constructed in order to fulfil psychometric and other important demands can be read elsewhere [21].

The determination of laboratory or physical parameters and their analysis is not a great problem in clinical trials nowadays. Referring to diseases such as GERD, in which the symptoms base on subjective perceptions, it becomes more complicated to judge between healthy individuals and pathological patients. Endoscopically, it is possible to make statements about the grade of GERD. In case of non-erosive GERD (enGERD), i.e. no esophageal lesion can be seen endoscopically, this distinction is impossible. Therefore, tools have to be invented that allow clear distinctions to be made between individuals suffering from GERD, especially enGERD, and individuals not suffering from GERD. Such a tool has to fulfil a lot of demands comprising validity, reliability, and responsiveness in order to be accepted as clinical outcome measure. In case of GERD, a lot of tools like diaries and questionnaires exist. Most of them lack of many features: they do not fulfil psychometric demands, they are limited with respect to layout or availability, or they base on wrong assumptions [22].

Actually, there is the problem to define what is considered to be 'ill' and what is considered to be 'healthy' in clinical studies. The establishment of cut-off levels or normal ranges is difficult bearing the danger of mistakes that can be made in every step of the development of new tools that will be invented as a help in diagnosing and judging patients' health status. Nevertheless, the introduction of normal ranges is an important step to take to improve the diagnosis in patients.

\section{References}

1 Sobel BE: Acute myocardial infarction; in Wyngaarden JB, Smith LH Jr, Bennet JC (eds): Cecil Textbook of Medicine, ed19. Philadelphia, Saunders, 1992, pp 304-318.

2 Bell NJ, Burget D, Howden CW, Wilkinson J, Hunt RH: Appropriate acid suppression for the management of gastro-oesophageal reflux disease. Digestion 1992;51(suppl 1):59-67.

3 Vaezi MF, Richter JE: Gastroesophageal reflux disease. Curr Opin Gastroenterol 1993;13: 327-332.
4 Dent J, Brun J, Fendrick AM, Fennerty MB, Jansens J, Kahrilas PJ, Lauritsen K, Reynolds JC, Shaw M, Talley NJ: An evidence-based appraisal of reflux disease management - the Geneva Workshop Report. Gut 1999;44:1-16.

5 Damiano A, Handley K, Adler E, Siddique R, Bhattacharyja A: Measuring symptom distress and health-related quality of life in clinical trials of gastroesophageal reflux disease treatment. Dig Dis Sci 2002;47:1530-1537.

6 Chiba N, DeGara CJ, Wilkinson JM, Hunt RH: Speed o f healing and symptom relief in grade II to IV gastroesophageal reflux disease: A meta-analysis. Gastroenterology 1997;112: 1798-1810.
7 Lind T, Havelund T, Carlsson R, Anker-Hansen $\mathrm{O}$, Glise $\mathrm{H}$, Hernqvist $\mathrm{H}$, Junghard $\mathrm{O}$, Lauritsen K, Lundell L, Pedersen SA, Stubberod A: Heartburn without oesophagitis: Efficacy of omeprazole therapy and features determining therapeutic response. Scand J Gastroenterol 1997;32:974-979.

8 Johnsson F, Hatlebakk JG, Klintenberg AC, Roman J: Symptom-relieving effect of esomeprazole $40 \mathrm{mg}$ daily in patients with heartburn. Scand J Gastroenterol 2003;38:347-353. 
9 Richter JE, Peura D, Benjamin SB, Joelsson B, Whipple J: Efficacy of Omeprazole for the treatment of symptomatic acid reflux disease without esophagitis. Arch Intern Med 2000; 160:1810-1816.

10 Hatlebakk JG, Hyggen A, Madsen PH, Walle PO, Schulz T, Mowinkel P: Heartburn treatment in primary care: Randomized, double blind study for 8 weeks. BMJ 1999;319:550553.

11 Richter JE, Kahrilas PJ, Sonntag SJ, Kovacs TO, Huang B, Pencyla JL: Comparing lansoprazole and omeprazole in onset of heartburn relief: Results of a randomized, controlled trial in erosive esophagitis patients. Am J Gastroenterol 2001;96:3089-3098.

12 Miner P, Orr W, Filippone J, Jokubaitis L, Sloan S: Rabeprazole in nonerosive gastroesophagel reflux disease: A randomized placebo-controlled trial. Am J Gastroenterol 2002; 97:1332-1339.
13 Richter JE, Kahrilas PJ, Johanson J, Maton P, Breiter JR, Hwang C, Marino V, Hamelin B, Levine JG, Esomeprazole Study Investigators: Efficacy and safety of esomeprazole compared with omeprazole in GERD patients with erosive esophagitis: a randomized controlled trial. Am J Gastroenterol 2001;96:656-665.

14 Holtmann G, Bytzer P, Metz M, Loeffler V, Blum AL: A randomized, double-blind, comparative study of standard-dose rabeprazole and high-dose omeprazole in gastro-oesophageal reflux disease. Aliment Pharmacol Ther 2002;16:479-485.

15 Moss SF, Armstrong D, Arnold R, Ferenci P, Fock KM, Holtmann G, McCarthy DM, Moraes-Filho JP, Mutschler E, Playford R, Spechler SJ, Stanghellini V, Modlin IM: GERD 2003 - a consensus on the way ahead. Digestion 2003;67:111-117.

16 Notes on scale construction. De Coster J, Department of Social Psychology, Free University of Amsterdam, 2002. (Accessed September 18, 2002, at http://www.stat-help.com/scale. pdf.)
17 Atkinson G, Nevill AM: Statistical methods for assessing measurement error (reliability) in variables relevant to sports medicine. Sports Med 1998;26:217-238.

18 Bland JM, Altmann DG: Cronbachs alpha. BMJ 1997;314:572.

19 Cohen J: Statistical Power Analysis for Behavioural Sciences, ed 2. Hillsdale, Lawrence Erlbaum Associates, 1988.

20 Canguilhem G: Le normal et le pathologique. Translated into English by Fawcett CR, Cohen RS. New York, Zone Books, 1994.

21 Armstrong D, Monnikes H, Bardhan KD, Stanghellini V: The construction of a new evaluative GERD questionnaire - Methods and state of the art. Digestion 2004;70:71-78.

22 Stanghellini V, Armstrong D, Monnikes $\mathrm{H}$, Bardhan KD: Systematic review: do we need a new gastro-oesophageal reflux disease questionnaire? Aliment Pharmacol Ther 2004; 19 : 463-479. 